\title{
Emergence and Transition in London's Climate Change Adaptation Pathways
}

\author{
Mark Pelling*,*, Thomas Abeling ${ }^{\dagger}$ and Matthias Garschagen ${ }^{\dagger}$ \\ *King's Centre for Integrated Research on Risk and Resilience \\ and Department of Geography \\ King's College London The Strand, London WC2R 2LS, UK \\ 'Vulnerability Assessment, Risk Management \\ and Adaptive Planning (VARMAP) \\ United Nations University-EHS, Bonn, Germany \\ tmark.pelling@kcl.ac.uk
}

Published 30 December 2016

\begin{abstract}
Climate change adaptation coevolves with urban development trajectories presenting decision-makers with a choice of positioning adaptation to protect or revise development. This relational view of adaptation in the context of large cities opens questions on the ways in which city and other actors interact. This interaction may be as or more important than resource and information access for shaping the adaptive capacity and direction of such assemblages. Transitions between modes of adaptation are little understood and will likely combine autonomous and deliberate change both incremental and transformative. Using London as a case study, the paper identifies the contemporary adaptation regime to extreme events and its lines of movement. Interviews and a scenario workshop with resilience planners and emergency managers show the orientation of London's adaptation is firmly positioned in a mode of resilience, protecting development through flexibility. Maintaining resilience to extremes under conditions of economic austerity is seen to result in the shifting of risk management burdens onto those at risk. Self-reliance is emerging as a mechanism for deepening the resilience mode of adaptation. At the same time, when considering potential risks for extreme events in 2035, most planners express a desire for more transformative adaptation that can tackle root causes in social conditions. A gap is revealed between the professional judgment of risk and resilience planning needs and likely trajectories constrained by national administrations and policy.
\end{abstract}

Keywords: Transition; transformation; London; adaptation; heatwave governance; TRUC.

\footnotetext{
${ }^{\ddagger}$ Corresponding author.

This is an Open Access article published by World Scientific Publishing Company. It is distributed under the terms of the Creative Commons Attribution 4.0 (CC-BY) License. Further distribution of this work is permitted, provided the original work is properly cited.
} 


\section{Introduction}

Adaptation to climate change in large cities presents an assemblage of interacting practices, technologies and discourses. Over time adaptation assemblages pass through multiple policy cycles (Howlett and Ramesh 2003) interacting with other public policy domains and activities (Stone 2002). These elements coevolve together (Zaidi and Pelling 2015) or periodically become locked in to more rigid states (Rotmans et al. 2001). Seen as part of the coevolving urban condition, assemblages of adaptation are at once intimately involved in the reproduction of social opportunity and wellbeing. This relational reading of adaptation emphasizes leadership, institutional context and competing planning agendas as key constraints (Measham 2011), alongside more established constraints of information and resource access (Inderberg and Eikeland 2009).

When adaptation is seen as coevolving with urban development trajectories, decision-makers are presented with a choice - adaptation can deliberately be deployed to protect existing development gains and processes, or where these are generative of unacceptable vulnerability and risk, development itself can be a subject of adaptation (Pelling 2011). Conceiving of adaptation assemblages as part of coevolving relationships between climate change risk management and development trajectories in the city raises questions about the relative dynamism of assemblage components and the surrounding social-ecological environment: why and when change occurs, how change is initiated and where it travels. Can adaptation keep pace with social-ecological change and indeed be anticipatory of such changes, or must adaptation be reactive? Who might the change leaders be in a specific context and what interests will block transitions in adaptation?

Greater London's climate change adaptation assemblage includes the policies, tools and actions of 32 local authorities, the Greater London Authority (GLA), national agencies such as Public Health England and the Environment Agency and a range of private sector and civil society interests as well as individuals and businesses at risk. Organizations themselves are composed of sub-units and individuals who also have agency (Pelling et al. 2007), while organizations exerting structural constrains on this agency will themselves be subject to the influence of national institutions (Measham et al. 2011). Within the city the balance between adaptation and development is held at a policy level by London's local authorities and the GLA as the primary agencies responsible for risk management but also for economic development policy. The GLA aims to "position London as an international leader in tackling climate change" (GLA 2011: 20) and in its London Climate Change Adaptation Strategy (2011) recognizes that adaptation can provide wider benefits, for example, by promoting green spaces. London's local authorities 
and the GLA are in addition influenced by interests in voluntary or mandated partnerships but it is through the lens of the local authority and GLA relationship that constraints and struggles over the relationships between adaptation and development planning can be seen most clearly.

Climate change is already being felt in cities through increasing temperatures and the flood risk associated with elevated sea level (IPCC 2014). London is exposed to extremes in rainfall and coastal flood and storm surge, drought, cold and heat shocks. The London Climate Change Adaptation Strategy (2011) projected that by the middle of the 21 st century, the average summer day will be $2.7^{\circ} \mathrm{C}$ warmer and very hot days $6.5^{\circ} \mathrm{C}$ warmer. By mid-century, most summers are projected to be the equivalent of 'heatwave' temperatures today (McCarthy and Sanderson, 2010 in GLA 2011). By the middle of the century, the average winter is projected to be 15 percent wetter and the wettest winter 33 percent wetter than the baseline average. Sea levels are projected to rise by up to $1 \mathrm{~m}$ by the end of the century, with an extreme scenario projecting up to $2 \mathrm{~m}$. An extreme scenario a $0.7 \mathrm{~m}$ increase in tidal surge height by 2100 has been projected. The Mayor's Regional Flood Risk Appraisal (GLA 2009), has revealed an estimated 1.25 million people and nearly half a million properties, extensive social and civil infrastructure (such as schools, hospitals and train stations) at high flood risk. Research by the Environment Agency has shown that the poorest 10 percent of Londoners are more likely to live in areas of tidal flood risk, and that both the richest and the poorest ten per cent of Londoners live at fluvial flood risk (GLA 2011). The growth of London will increase the number of people living and working on the floodplain, and the associated assets at risk would also increase. This would be the case both within Greater London and surrounding commuter towns, especially those in the Thames Gateway which lies within the Thames floodplain (Royse et al. 2010).

Adaptation, including to climate and weather extremes, requires an ability to learn and act on that learning (Inderberg and Eikeland 2009). In London, emergency services, urban planners and resilience planners working for local authorities and the GLA share technical viewpoints to help connect across political and organizational interests and mandates, and with science enabling interaction. Capacity to act is strongly constrained by national policy especially since 2012 as legislation associated with the current period of austerity has reduced planning guidance and budgets to local authorities. At the time of researching, UK local governments have recently experienced a 40 percent cut in resources (Local Government Association 2014). So-called austerity politics have cut risk management and resilience officer posts and forced public sector agencies to retreat to the core protection roles of risk management. The economic implications of BREXIT seem likely to deepen this challenge for London. 
In the GLA, resilience planning has been repositioned from being a voice for integrated development and risk management planning located at the policy core of the Mayor's Office to sit within a more marginal technical bodies — the London Fire Brigade and Mayor's Office for Policing and Crime and is now associated with a more narrow risk management and civil protection agenda. At the same time, there is recognition of growing social inequality in the city and its expression in hazard exposure and vulnerability. Once links are made between equity and risk, social policy becomes a more central tool for risk reduction and London is among those cities where the link is becoming increasingly clear. What are the implications of these dynamics for Greater London's adaptation pathway? What actors and processes lie behind these movements and are they amenable to further transitions?

To approach these concerns three questions are asked in this paper.

- What are the current relationships between risk management, climate change adaptation and development?

- Is there evidence that a transition to a new risk management pathway position is desirable among practitioners?

- If there is a desire for transition how will this be enabled or constrained by the current organisational and policy architecture for adaptation and risk management in the city?

The paper is part of a wider analysis of climate change adaptation transitions in coastal megacities supported by the Transformation and Resilience on Urban Coasts (TRUC) project see www.bel-truc.org. A common analytical framework (Solecki et al. 2017) and methodological tool kit has been deployed across these cities which includes Kolkata (Narayanan et al. 2017), Lagos (Ajibade et al. 2017), New York (Link and Solecki 2017) and Tokyo (Nishi et al. 2016). Analysis presented in this paper draws on data collected in 2016 through a workshop with 15 participants and subsequently 19 expert interviews with risk and resilience managers employed by local authorities, the GLA and national agencies with remit in London.

This paper is organized into four sections. The following section discusses transition in risk management and is followed by a discussion of results organized by the three questions presented above, and final conclusions.

\section{Transition in Urban Risk Management and Sustainable Development}

Observed and projected increases in climate variability and extremes move disaster risk management towards the center of efforts to secure a sustainable development 
(Schipper and Pelling 2006). In large cities, disaster risks require management through responsive mode emergency services, but also through risk reduction delivered by closely integrated sectoral planning to ensure risk management is comprehensive (Revi et al. 2014). This more inclusive and comprehensive vision of disaster risk management aligns existing work much more directly with ongoing social, economic and cultural dimensions of sustainable development and tradeoffs between them, and is likely to require transformational change in disaster risk management.

There is growing recognition in adaptation literature that governing transformational change requires transformation of governance systems themselves. However, the speed, scale and depth of deliberate transformational change is challenging for policy makers and the public. Some suggest that transformational outcomes could be delivered through incremental steps as well as transformational moments (Pelling 2011; Kates et al. 2012). But also that incremental steps limit ambition and so can undermine transformative movements (Pelling et al. 2015). Tremeer et al. (2016) offer move beyond this impasse by proposing the notion of continuous transformational change. This recognizes incremental and transformative change can coexist, and that transformations can be emergent as much or perhaps more than being planned. This blurs the duality between autonomous and planned adaptation so that processes of change may merge serendipity, accident and deliberation.

Transformation is used in the literature to describe both a process of change and an outcome. Here, we distinguish between outcomes and process by describing the process of change as transition. This leaves open the possibility that incremental and/or transformational processes and acts can shape transitions to transformative outcomes. Transition can unfold between a number of states in the adaptation-development relationship. Transformation is used to describe adaptationdevelopment relationships that accept change in development is required to reduce risk. Similarly resilience describes relationships built on the goal of flexibility in development and resistance an orientation that presents adaptation in risk management with the goal of preventing change in development, collapse describes those relationships where no strategic linkages exist. Table 1 presents and exemplifies these four relational positions (Solecki et al. in press).

Development is taken to describe the structures of governance, physical technologies and dominant customs that determine the social and spatial distribution of socio-economic and ecological wellbeing. We are interested in the extent to which dominant adaptation-development relationships and transition from one status to another can be described for megacities and if this is moving London closer to sustainable development. 


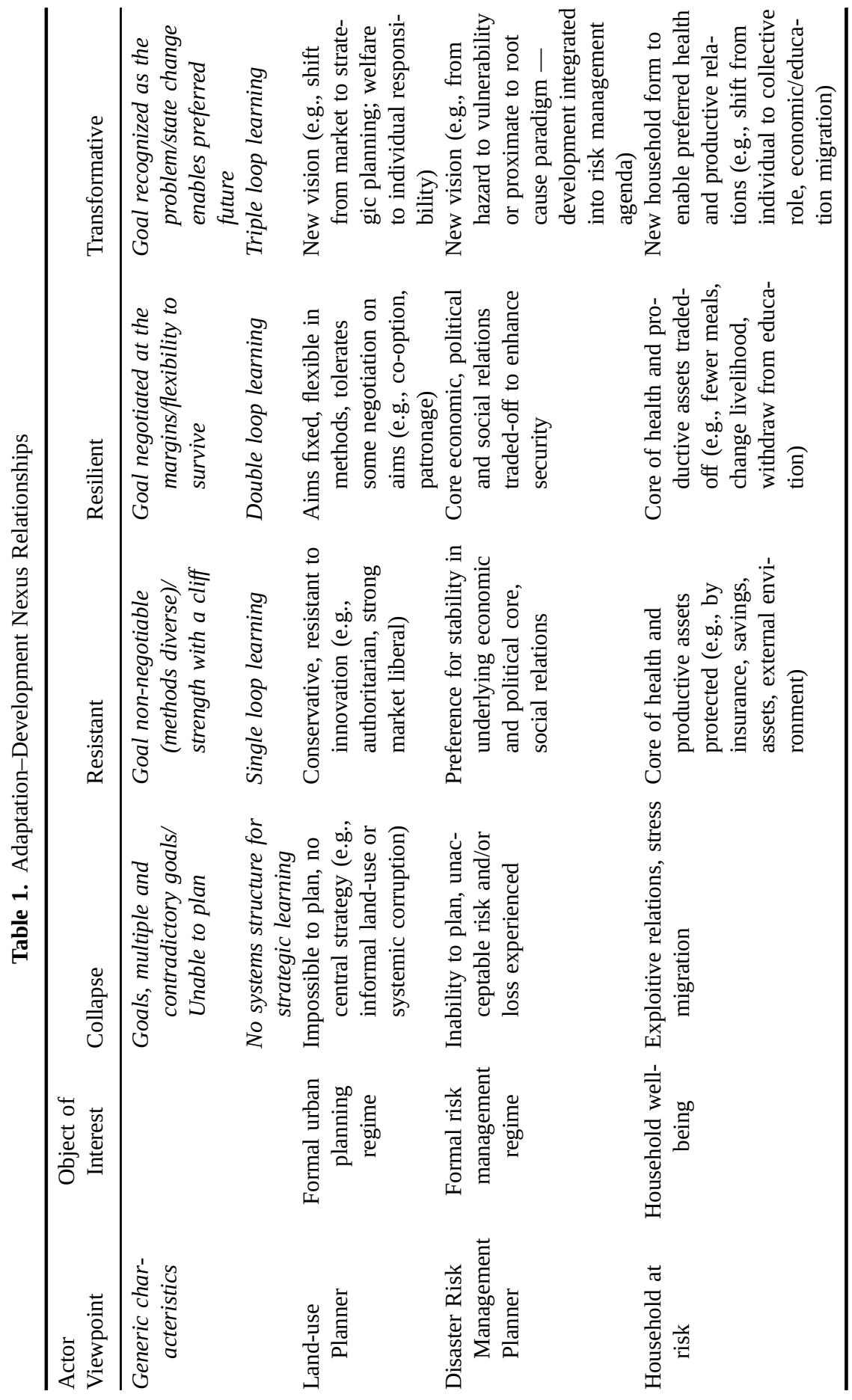


Observed development-adaptation relationships will be messier; more multiple, dynamic and contested than Table 1 implies. They are used here to locate stakeholder perceptions of the development-adaptation relationship to open a conversation on transition. No hierarchy of preferred development-adaptation relationship exists. This will be dependent on context and viewpoint, movement from one mode to all others is considered possible. Transition, weather by autonomous or deliberate will unfold within the adaptation assemblage. Drawing on Harvey's (2010) methodology of moments, Pelling et al. (2015) propose seven activity spheres that map where transitions can unfold:

- as discourse in political claim making,

- as technological innovation,

- as reform in administrative and legal systems,

- as a shift in economic orientation or individual livelihood,

- as an awakening of alternative values,

- as restructuring in physical and ecological systems,

- as an assertion of new practices ad routines of behavior.

Observing where transition emerges and the pathways through which it is channeled can help prepare megacities for necessary transitions ahead. Understanding better points of blockage or acceleration, and processes by which transition in one activity sphere influences another can be important tools in shaping urban development pathways that are adaptive and can move towards the procedural and distributional equity goals of sustainable development.

Two participatory methods were used to identify risk management and resilience planners' views on current adaptation planning and potential for transition in London. While an analysis of viewpoints is presented in this paper, the wider aim of the TRUC project was to provide spaces for planners to reflect on the vision, organization and practice of adaptation and consider strategies for transition. The first engagement with practitioners was through a one day scenario workshop. The aim of the workshop was to identify participants' collective views on the relationships between London's development trajectory and its scope for adaptation. This was followed by semi-structured interviews with participants and additional respondents unable to attend the workshop. Respondents were asked to identify the aims of current adaptation planning and which agencies had been most important in shaping this position. Four extreme future risk scenarios were presented and respondents asked to consider if transition in adaptation through risk management would be appropriate to better secure sustainable development. The deployment of two methods allowed for triangulation and provided participants a period of reflection between events. 


\section{Results}

\subsection{What are the current relationships between risk management, climate change adaptation and development?}

The aim of risk management in London is overwhelmingly perceived to be resilience - to protect existing development practices and land-use while being flexible to better live with risks. Within this many respondents recognized an increasing focus on self-reliance. Referring to the Pitt Review (UK Government 2007) - a national review of flood risk management folding flooding in 2007 — the Head of Emergency Planning from an inner London borough pointed out that:

\section{If you build near a river you need to know that you have to look after yourself. This push towards stronger self-responsibility has happened in particular over the past five years or so. I think it was because of the Pitt Review that it happened.}

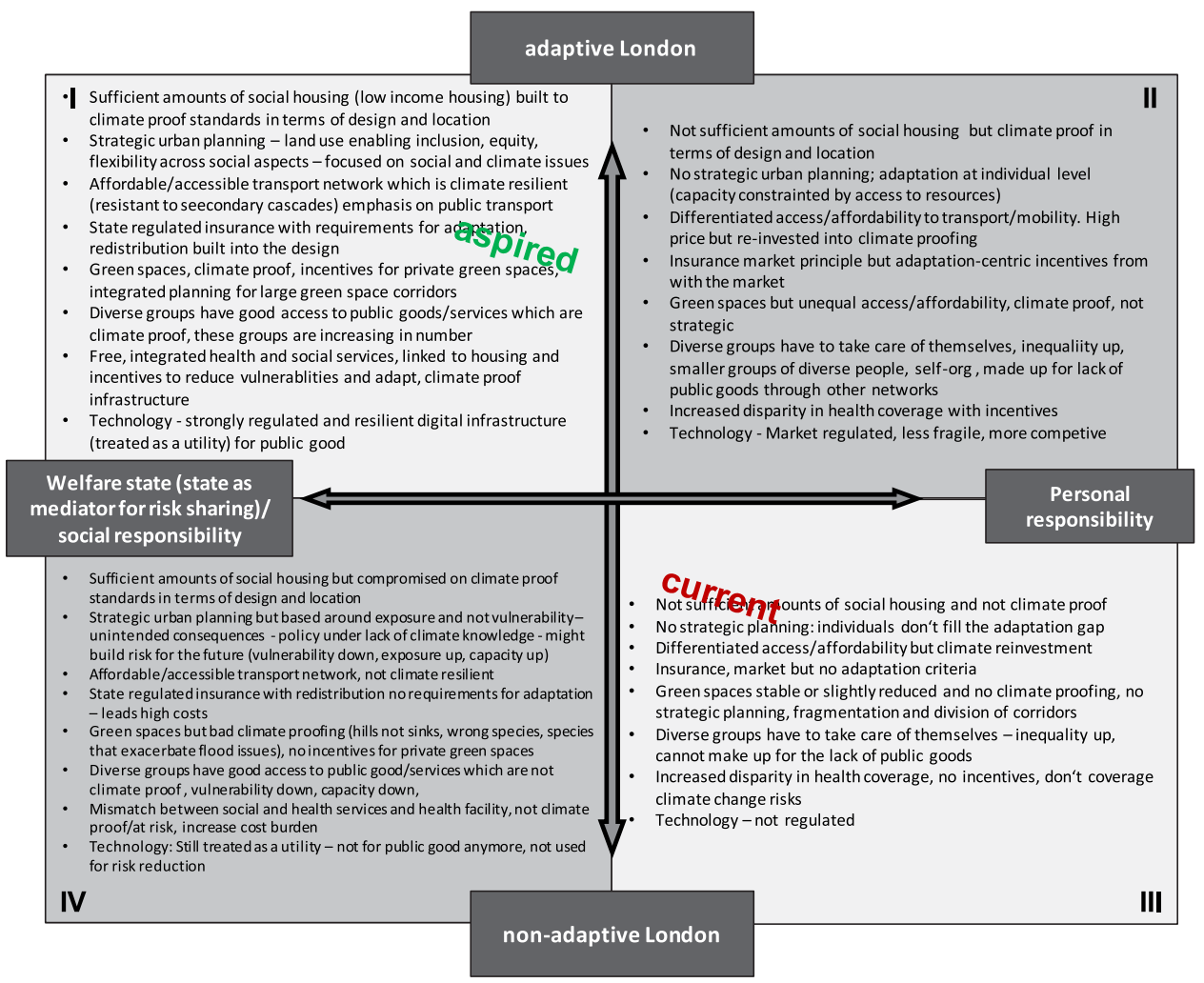

Figure 1. Climate Change Adaptation and Development Scenarios for London 
Figure 1 reinforces this assessment, here workshop participants described London as only weekly committed to adaption with state actors having reduced capacity and with a generally high burden of personal responsibility for risk mitigation ('current' in Figure 1). Respondents shared an aspiration for a more adaptive city, although the degree to which this should be best achieved by increased state or personal action was more contested. Even though a strong welfare state assuming a high degree of social responsibility was perceived as desirable, participants maintained that personal responsibility for risk mitigation ought to be strengthened and motivated.

London has been growing increasingly unequal, driven in particular by a crisis in housing supply (Travers et al. 2016). This has not been a core consideration in determining adaptation policy for London to date. The lack of attention to London's rising inequality in risk planning may be reflected in the influence of national as well as city level actors for the contemporary positioning of adaptation, and the role of science and business interests. Within these levels of activity technical agencies, rather than politicians including the London Mayor were perceived to be most influential, reflecting the technical content of adaptation and risk management plans. The media and local authorities were also regarded as influential. Civil society was perceived as having little impact on shaping the current regime orientation - again indicative of technical/professional leadership in risk management and the challenges faced by efforts to promote a social vulnerability approach.

The influence of national level initiatives on London's adaptation position was illustrated by two national policy outcomes: the Pitt Review (2007) and National Heatwave Plan (NHP) (2004). The former stimulated a range of local authority and GLA reflections on flood risk management and the latter continues, through its

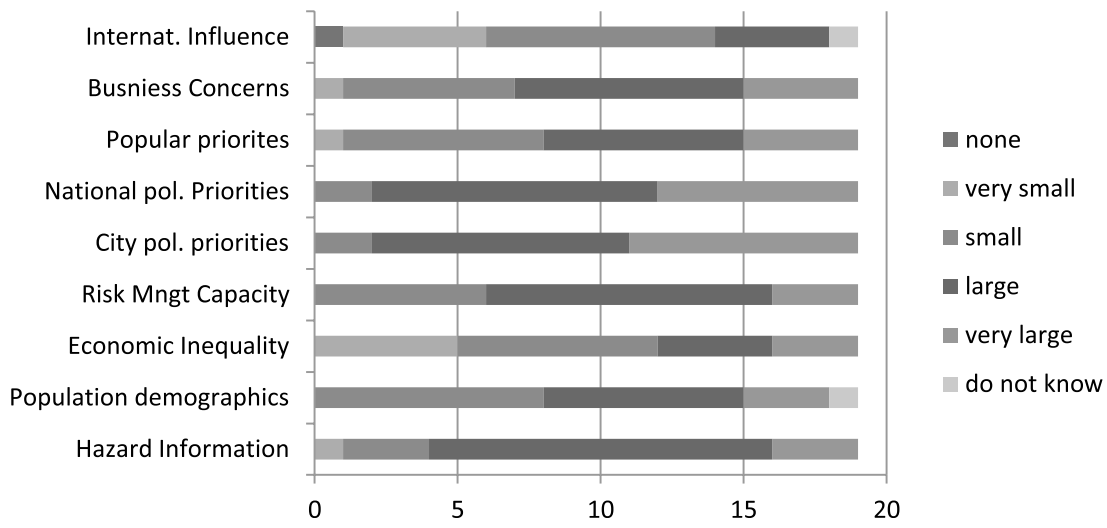

Figure 2. Factors Influencing Orientation of the Current Adaptation Pathway 


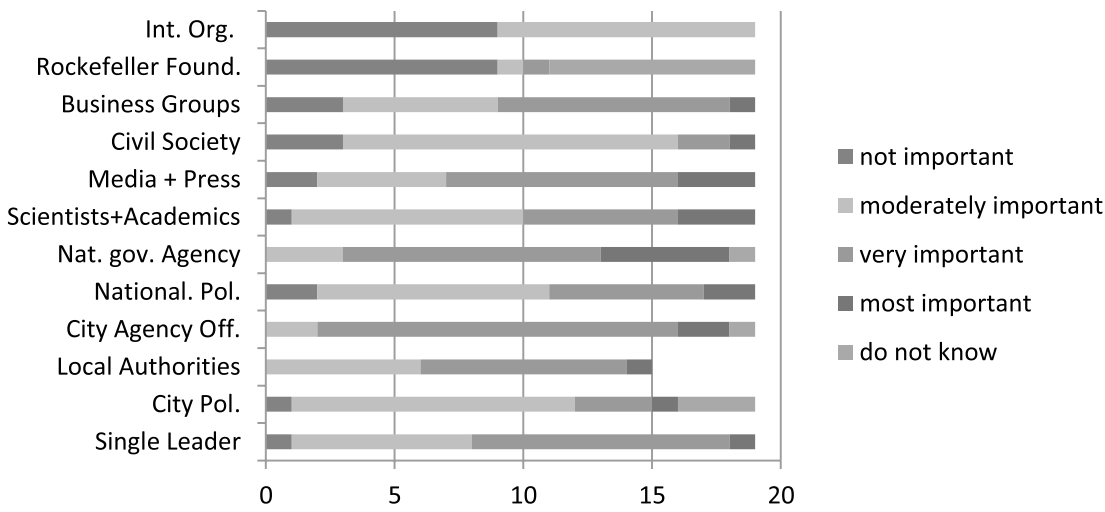

Figure 3. Actors Influencing the Current Adaptation Pathway

annual revisions, to set the agenda for heatwave risk management in the city. The NHP is increasingly pushing for transition towards a more joined-up social care model of resilience, but to-date risk management continues to be delivered through medical responses and long-term and urban design and planning. Both processes were responses to major events, flooding across the UK in 2006 with limited direct impact on London, and a national heatwave in 2003 with a strong impact on London.

\subsubsection{Drivers and constraints for transition}

Under London's resilience regime, growing economic inequality will likely increase the relative burden of self-reliance on households. Most at risk will be lower-income home owners who tend to be more exposed and susceptible to the impact of extreme events, and have limited resource to cope including through reduced take-up of private property insurance (GLA 2011). Respondents identified the high costs of flood insurance as a primary reason for lower-income home owners to be more exposed to risk. In particular, respondents confirmed housing analysts' views that a combination of high value private sector housing and property investments in central London and changes to social support entitlements were driving a significant wealth gap and increasing inequalities between affluent areas along the River Thames and more socio-economically challenged areas, predominantly in outer London boroughs (Marom and Carmon 2015).

Growing tension was perceived between affordable insurance as part of a resilience orientation to adaptation and the persistence with which public opinion holds the state as an insurer of last resort. This was considered as a potential tipping point for transition towards transformative adaptation by a senior policy manager at the GLA. A? respondent suggested that potential legal disputes over 
insurance claims could put pressure for policy change nationally with implications for London:

The availability of affordable insurance will also play a big role. In the next years we will see a legal challenge over something that gets flooded and that was insured, and that will flip policy, I believe.

A resilience orientation to heatwave risk management was criticized for being reactive and failing to address the more fundamental changes required for sustainable risk management. In the view of one respondent:

It's about “be aware” rather than "let's grow some trees". It's reactive rather than proactive. Cool rooms are there, but there is nothing about how you can create them. Nothing in the heatwave plan that really helps me to do forward planning. It says things like “drink more when it's hot”. It's like. .yeah, ok, but what about building design, landscaping. We have all these regulations that say buildings have to be accessible, but nothing that says they have to be livable.

The high costs of retrofitting existing buildings and for systematically integrating cooling in new building design were perceived as a barrier to transition towards a more transformative orientation in adaptive to heatwave risk. Referring to an in 2013 when an inappropriately designed building magnified sunlight damaging cars (see http://www.bbc.co.uk/news/uk-england-london-23930675), a risk management officer from Health England stated:

It's this classic example of the Walkie Talkie (20 Fenchurch Street) where you design a building that ends up burning your car. The evidence is here, but planning laws are just ridiculous. In our planning laws, we have a lot about aesthetics, a lot about fire safety. But we have not built in climate change. This is because of the financial impact that it would have, I believe. If you put in forward-thinking people will look at you and go "Really? That is what you expect me to spend?"

The high costs of retrofitting existing building stock in London points to a limited potential for physical adaptation to heatwave risk in the city and an example of lock-in. Even if policy were to transition regulating building design, impacts on the ground might unfold only incrementally over long periods of time. This form of lock-in points to the importance of developing effective planning and building 
regulations now for adapting building stock to risk anticipated for mid-century. With the right incentives private and public sector property owners could reorient quickly. However, the Head of Emergency Planning from an outer-London local authority underlined how a lack of available resources and the limited space in central London constrained such future-oriented considerations of climate risk:

Because of the resources, the space, the money that we have got I think that everybody accepts that there will never be a perfect approach. Many things that matter for heatwaves, like the building structure and the planning, are already locked in. Unless we would build a new city from scratch, it is about trajectories.

The Head of Emergency Planning from a London local authority argued that advice on building design in the NHP would fail to address problems with existing building stock:

The NHP does spell out that these long-term planning issues are important, issues like building design etc. The challenge is that a lot of buildings are old, and the advice is rather targeted at new developments. In many ways I think the advice does not fit the realities.

GLA as well as local authority level agencies were united in a concern for the apparent difficulty in formulating effective, actionable strategies to adapt existing physical infrastructure in London to extremes. The London Fire Brigade suggested that a failure in risk management policy to address lock-in effects of heatwave vulnerability was acknowledged in the wider risk management community of practice in London, stating:

Councils and the health services they often look at planting trees, at greening, and at increasing natural cooling. Everywhere we try to improve natural ventilation. All of this, however, seems to be for new developments, for new buildings. I am not sure what we do for old buildings, for those that already exist.

\subsection{Is there evidence that a transition to a new risk management pathway position is desirable among practitioners?}

Within the next 20 years (by 2035), respondents expected current trends in extreme weather to intensify with: changes in environmental and biophysical hazards (more floods, more heatwaves), socio-demographic changes (especially aging) and economic inequality aggravating future risk and adaptive capacity. A majority of 
respondents also suggested that a governance capacity for adaptation and risk management in London would continue to decline. In this context, concern that the current resilience approach and drift towards self-reliance would not be able to adequately prepare the city for future risk scenarios was articulated by both local authority and GLA agencies. The Head of Emergency Planning from an outerLondon borough suggested that a growing city population would be among the most significant future risk factors:

The sheer quantity of people and the density that comes with it will require a shift towards more fundamental changes in risk management. The infrastructure that needs to be added, and the changes in the climate and the impact that this will have on London also play into this.

A similar view was expressed by a senior policy and program manager at the GLA, who reflected on the need to transition from current planning practices to help face potential extremes in future risk scenarios. The GLA 2015 population projections project the total population of Greater London to rise by 2.35 million between 2014 and 2041 to reach 10.89 million (see https://data.london.gov.uk/dataset/2015round-population-projections). According to the respondent, current infrastructure capacity would not sustain this significant increase in population in London:

We will have three million more people in London quite soon. We have already stretched our infrastructure for the past 100 years. We can't keep stretching it like that. So how do we get towards less demand on infrastructure and to new infrastructure that is designed for climate change? It means we need to do things differently than we do today.

To help gauge the relative importance of these factors in provoking a transition respondents were presented with four scenarios for London in 2035: (A) a doubling of hazard intensity and frequency; (B) hazard doubling plus a doubling of the population over 65 years of age; (C): a doubling of hazard, aged population and social inequality, (D) a doubling of hazard, aging, inequality and a halving of risk management capacity. Given these extreme scenarios, respondents agreed that transition to a more transformative regime in London was inevitable by 2035, but differed in the primary tipping point for transition (Figure 4). Scenario C (more heat/floods + aging population + social inequality) was most often considered the tipping point for transition. This indicates a strong degree of perceived robustness in the current risk management system and reinforces the importance of social inequality as a rising driver for transition. 


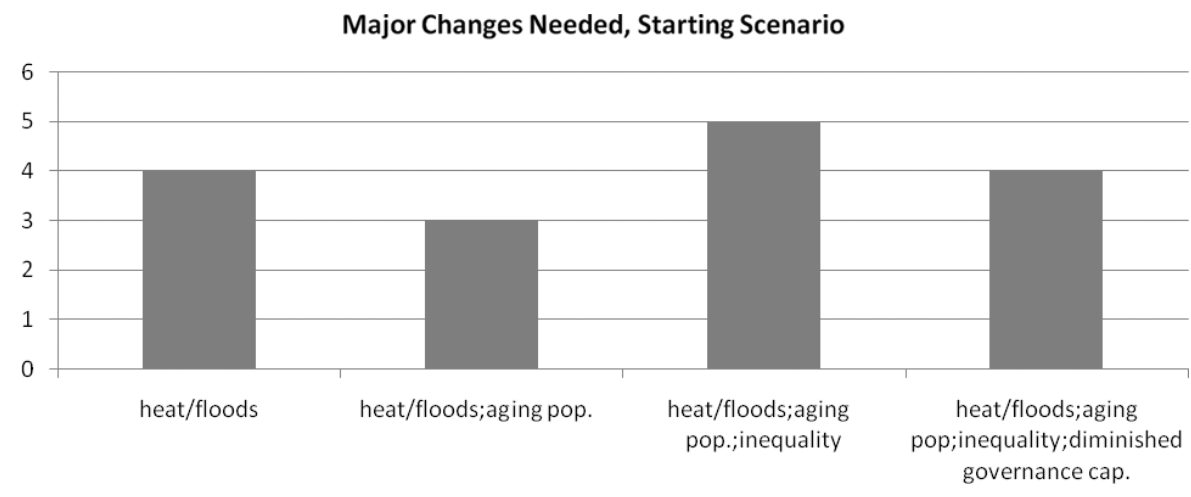

Figure 4. Starting Scenarios for Transformation in Risk Management

Growing social inequality was seen by all levels of London's administration as a challenge that would require fundamental changes in the way that government assistance to citizens should be targeted in times of emergency. Respondents expected that under increased inequality many more people in London would depend on government assistance, putting further pressure on the public sector to provide services. A climate change officer from a London local authority suggested that growing inequality would further aggravate problems of the poor to access insurance so putting pressure on the self-reliance model of adaptation that is currently being emphasized:

\section{"This would mean we would have more people depending on government assistance during a crisis. For economically mar- ginalized people it would be harder to get insurance, there would be very little capacity to adapt your own dwelling and to respond on your own."}

Inequality raised a policy challenge for resilience: Is it possible to both enhance social justice and redistribution goals, and self-reliance? Respondents acknowledged that if major changes to risk management were needed city-wide, national government assistance to vulnerable people would have to be targeted more precisely, to prevent costs escalating. To achieve such a change in resilience planning that would embed it more firmly in economic development policy political support from the Mayor of London and from national government would be needed. Providing measures to support those unable to self-protect would likely need to invoke reform to local, city or national tax regimes or through enhanced employment opportunities for people with lower socio-economic and 
educational status, according to a senior manager at the London Resilience Team:

I am not sure that we would cope well with significant inequalities. I think to respond to this scenario (more social inequalities) would need a massive transfer in resources from the rich to the poor. This could be done through taxes, but also through a more equal access to employment opportunities.

Increased social targeting of public sector support was also seen as inevitable, according to a respondent from the London Resilience Team:

(...) we would need to really go back to the core of what government is there for, to the core of the purpose of government and the public sector. It would entail changing what gets responded to and what not. In this scenario, it is not about risk reduction in a broader sense, but the diminished governance capacity would force us to focus on business continuity. This inevitably puts more people at risk, and we would have to cherry-pick what gets a response.

The identified need for more a transformative orientation in adaptation and risk management under the 2035 risk scenarios discussed with respondents is summarized in Figure 5. Resilience and resistance remain in this future vision, but are both much reduced.

\subsubsection{Austerity and self-reliance: A contemporary driver for transition}

Austerity has already been felt through a transition towards resilience through selfreliance. The Head of Emergency Planning from one inner-London borough envisioned further austerity programs limiting risk management interventions to public information services. The public sector would be forced to retreat into only enabling disaster affected communities to help themselves, direct intervention would be hard to justify with deeper austerity.

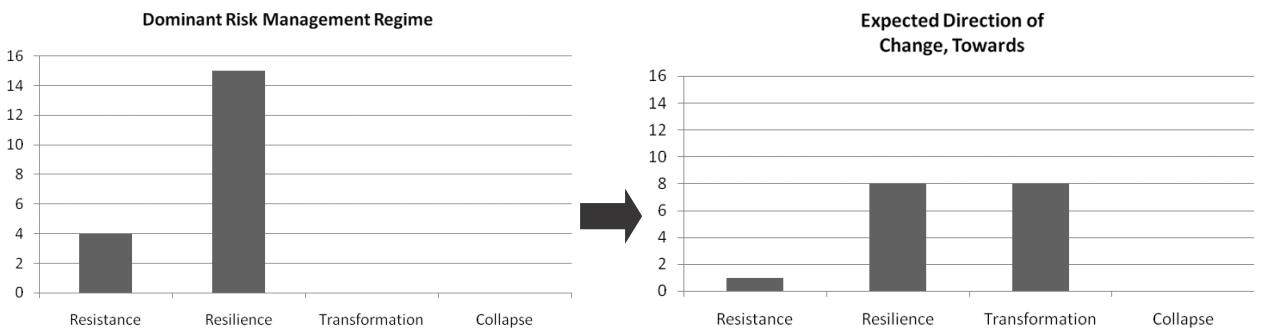

Figure 5. Expected Direction of Change in Risk Management 
"It comes down to public information. The paradigm that underpins this approach on information is self reliance. People have to help themselves. 50, 60 years ago self-help was built in the system, it was expected that everybody looks after themselves. This ethos has been lost in the past couple of decades, but with austerity it is back. In a way we are establishing old ways in a new world.”

A senior emergency planner from a London local authority noted that delivering mandated responsibilities under austerity had led to public-private partnerships and a larger role for private sector stakeholders alongside self-responsibility and 'community resilience' in meeting public service delivery aims.

"We are already facing significant cuts in government resources. We already have to adopt policy that means an increase in private sector investment into public policy, because this is more sustainable. Already we are putting a lot of emphasis on building community resilience, about promoting ownership and selfresponsibility. This would continue to be the dominant approach. The private sector is where the money is. Government activity in this scenario would be about building partnerships with the private sector and giving them direct responsibility for risk management."

The effects of increased targeting for risk management can already be seen. This includes science-based rationalizing of resources such as Fire Stations and Public Health Centers. A risk management officer at a local authority suggested that evacuation and care provision for disaster affected people had already suffered significant cut backs in recent years. This was now targeted much more strongly towards directly affected people. While such a targeting approach might increase efficiency in government spending, it also potentially aggravates existing inequalities in the capacity of people to help-themselves:

"I think we would see a complete change in government mindset here. Risk management would be that people have to look after themselves. There would be no calling of 911 anymore; we would have to help ourselves. So risk management would be about helping people to help themselves. That would be the norm. I think we are close to that tipping point already. It used to be that if we had a fire, for example, it would be about evacuating all people from the building, set up temporary shelter, treat them as guests, 
look after them, provide food, drink etc. Now we ask: ok there is fire on the 8th floor, so who really needs to get evacuated from the building. Probably the people on the 3rd floor are fine. We then expect that people seek accommodation themselves, and that they return as quickly as possible. The problem with that is that it matters how affluent you are. The less affluent the more you need help from the government. If you have money you can buy insurance, but if you are a migrant with no money and no social networks you have nowhere to go."

A similar view, already identifying a shift towards self-reliance and community resilience from a Head of Emergency Planning in an outer London borough expressed concerns about potentially negative implications for disaster affected communities:

"The problem is that many people might do the wrong things if they are asked to do them themselves, that they interpret their responsibility wrongly. A basic responsibility to care for people will always shape local government actions. But the paradigm will be more strongly about self-help, and those that are financially able to help themselves."

\subsection{Capacity and trajectory for transition}

Strategic transition in London, in any direction, was considered to require leadership, or at least support, from national government and government agencies. Without political goodwill and technical expertise deliberate transition was considered unlikely to be successful. In addition, two city level groupings of actors were consistently identified as critical for transition, both offering potential catalysts and champions for change in the adaptation-development nexus (Figure 6).

First, the Office of the Mayor and its technical partner the GLA. The Mayor's Adaptation Strategy for London is an example of a? London-based initiative and a vehicle for transition that pushes towards the transformation desired of many stakeholders. It offers a vision of a more preventive and a forward-looking orientation to climate risks. But the power of the Mayor and GLA to enact this transition is limited by the availability of resources. A senior climate change manager at the national level Environment Agency pointed to this opportunity and constraint:

"The proactive elements are in the Mayor's Adaptation Policy. It really called on being proactive. We are now starting to develop 


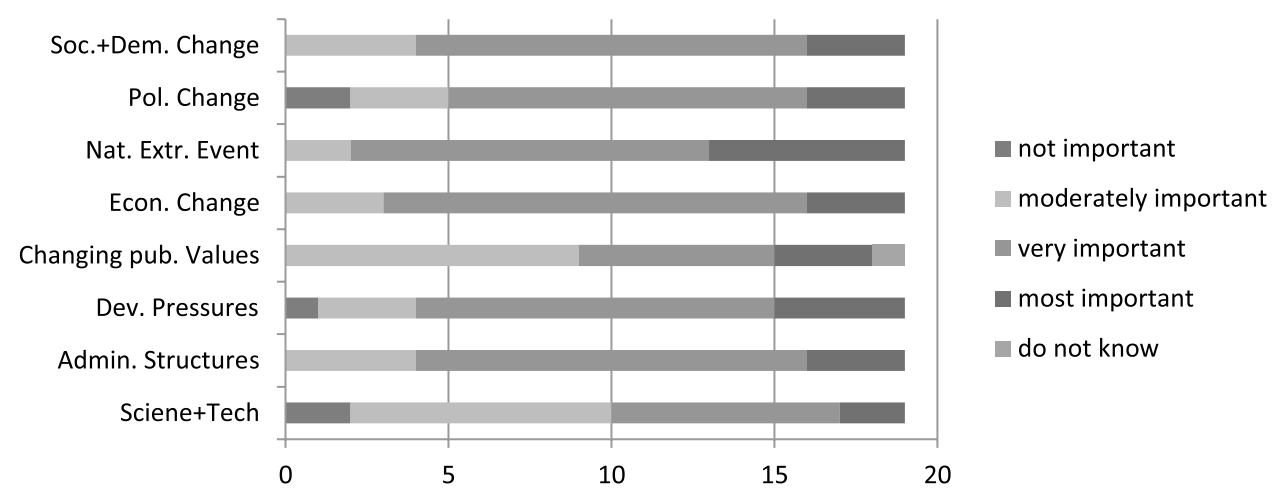

Figure 6. Drivers for Policy Transition in London

policy around future pathways. These are not precise scenarios of what will happen in the future, but it starts to get us thinking about what we need to do. There is no funding for it yet, in fact we have to try to put the money in ourselves. It is already there on paper, we have it in the adaptation strategy, now it is about moving it to decision making."

A second actor base arises from collaborations between scientists, disaster risk practitioners and local authority political leaders. The Head of Emergency Planning from an inner-London argued that bottom-up transition in London required this collaboration:

"I think three main actors would be particular important. Scientists and academics that provide in depth policy relevant knowledge, experienced risk managers and contingency planners that can put this knowledge in practice, and political leadership to support them in doing so. Alone none of the three could make a difference, it takes the collaboration."

While it is possible to point to national policy that has stimulated movement in London, for example the Pitt Review and NHP, both are reactive. National policy has a history of following rather than anticipating events. This is problematic for managing climate change in the concentrated risk and dynamic social and environmental landscape of London. A senior risk management officer at Transport for London saw this culture as very difficult to shift: despite increasing levels of risk in London, the resilience approach would likely continue to be shaped in a reactive way, by major events, and would remain responsive, prioritizing lessons that help 
to avoid past disasters in the future, rather than anticipating potential future events that had not yet materialized:

\begin{abstract}
"I don't see any change happening here in the future. I think at the moment, we are in the calm before the storm, as the environment changes, the population changes. Risks are becoming more likely. In the long term I think any change would depend on disasters to happen, but the overall aim would remain a protection of development, it would still be stability oriented. If a major disaster happens all changes are around how you can better respond for the next one, and you keep that until the next disaster happens."
\end{abstract}

This view is echoed by respondents who identified natural hazard events as the most important driver for policy reform (Figure 6). Notably limited in impact were changing public values and science and technology innovation and advice. This reflects also the wider character of planning in London which is heavily influenced by the aims of national agencies. Indeed the Head of Emergency Planning from an outer-London borough suggested that transition in London would need a new, joined-up political vision and a shared understanding of the aims and prospects of such a change across government and wider social actors, including business:

"It is already out there, people try to bring about transformation. But there is no clear idea of what transformation is. Rather each agency seems to have its own idea. There is no joined up approach between different agencies, and there is also a clash between government and business."

\title{
3.3.1. Barriers to transformative regime transition
}

Political cycles were highlighted as a significant obstacle for transitions to longterm, preventive risk planning. A senior risk manager at the London Fire, Brigade suggested that electoral cycles undermined political support for planning beyond 5 year time horizons, and expressed little confidence that risk management approaches would change fundamentally in the next 20 years:

"Our risk management approach is not transformational because of the political influence on it. I don't think we will ever have a long term strategic approach. It is very much driven by the 5 year political cycles. There just is no long-term planning for 20-30 years. The mindset is "let's see how much we get and let's try to chop away a minimum and do as much as we can with it." 
Limited political support for planning transitions was also linked to the challenge of demonstrating value-for-money in the short term. According to a senior risk manager at Transport for London decision-makers are very sensitive to the need to demonstrate impact and this is not easy with risk prevention unless in responding to a major event, as in the Pitt Review and NHP:

\begin{abstract}
"People do not want to think about risks in 20 years time if it costs them money to act on it now. This is why I believe risk management is so important, but also why it is so difficult. We always have to justify what we do. If we focus on what could happen and it doesn't, people think its resources wasted. If we alert people to risk and they then happen people will question why we spent the money on risk management if we can't prevent it from happening."
\end{abstract}

This dilemma of successful emergency planning and risk management was also highlighted by a respondent from the GLA. The respondent linked the phenomenon to culturally-rooted public expectations about the role of government, and the services that it should provide to the citizens:

"A barrier is also the question of how we can celebrate success. When you successfully adapt and prevent something bad from happen, that does not make the news. People will just expect this from government. So there is a lot here about cultural expectations about the role of government."

Resource constraints affected all levels of governance in London, and seemed to diminish significantly the capacity of risk managers to implement existing and develop innovative risk management policies. A senior manager at the London Resilience Team argued that individual agencies were increasingly focused only on fulfilling responsibilities mandated by the 2005 Civil Contingencies Act. This left little room for maintaining relationships with other partners and for collective reflection on goals and practical or strategic that might enable transition:

"For heatwaves we have very fragmented responses from the agencies. Everybody has its own plan. The National Heatwave Plan is an NHS Plan it is focused on health and does not cut across agencies. Individual agencies have individual actions. I think this lack of strategic approach is because the government has not priority for heat stress, so it is simply down to individual agencies to meet the legal obligations by implementing some plan." 
The Head of Emergency Planning from an outer-London local authority described how staff cuts had affected information sharing and effective coordination between different agencies and lines of government in London, exacerbating the fragmentation that many explained as the fundamental challenge to strategic transition

"Political change is quite disruptive, and the short-termism that comes from the political cycles. It can be very inefficient if you have to go back to square one after four years. Financial limitations at all levels of government also play a huge role. It leads to a resistance of agencies to engage with people and the communities that they are part of. I see it with a lot of colleagues here in London, that often have to say "sorry, we can't come to that meeting, there is just too much we have to do."

A policy manager at the GLA suggested that investments in climate adaptation often lacked direct financial benefits, and that this undermined the scope for action of stakeholders supporting transition. Developing pricing schemes for adaptation actions emerges as a potentially important step towards a stronger commitment for adaptation projects:

"The problem is that there is no price for adaptation. We value it, but can't really put figures to it. We deliver against a nonstationary target. With climate change, we need to deliver a lot just to hold us where we are. The people who pay for adaptation and the people that benefit from adaptation are not linked, that makes it really difficult to make the case for significant payments that need to be made."

Complacency was also cited as a constraint on transition, allowing questions on future risk to go unasked and avoiding the opening of a policy agenda from transition at a time of fragmented governance and public sector austerity:

"What is also a problem is the fact that since we are London, many people think we are already good at things. There is a bit of arrogance here. In Canary Warf they had people from New York come over to look at how they do their security arrangements. That makes people feel we are already the top players, but there is so much where we are not strong. Why are we not trying to learn from others?”

In summary, responses indicate limited scope for transition to a more transformational approach in London. Most respondents expressed little confidence that 
the aims of risk management in the city would change significantly from resilience over the next 20 years. However, broader social and economic developments, most notably funding-cuts and diminishing government capacity suggested creeping changes towards a stronger role for self-reliance and individual ownership of risk. The transition being observed is then not planned but a bi-product of national political values and steering. This meets the fears of respondents that London is moving towards a more unequal future for risk management.

\section{Conclusion}

London's current resilience orientation to climate adaptation is intensifying. Movement is towards a greater emphasis on self-reliance and is enabled by the policy discourse of resilience. This is less a strategic policy choice than an outcome of national austerity measures aligned with the mandated requirements of local authorities and the GLA. The result is that in a period of social and economic change and in the face of increasing environmental variability and extremes, public investment in risk management is decreasing and the responsibility for this is being placed on the shoulders of individuals. For some, this will be a positive experience, but for those with limited resources, especially lower-income home owners, there are dangers of being unable to fill the gap left by a retreating public sector. Perhaps most concerning are at risk, marginal populations (the elderly, migrants and local income groups) where hazard exposure and vulnerability may be high but awareness of shifting responsibility low and capacity to take on the burden of adaptation through personal risk management is low.

The tension between self-reliance and austerity in this adaptation assemblage generates an adaptation gap. This gap has not yet been squarely addressed in London. In part, this is because the shifting movement is unplanned while the management systems are complex, involving multiple agencies and levels of government and the political costs for engaging with social justice may be unpalatable for decision-makers. Nevertheless, if self-reliance is a de-facto policy position this will have implications for the social and spatial distribution of risk in London and eventually for risk management resource allocation. The potential scale of the adaptation gap led respondents to identify new tax regimes and employment as well as risk management policy as falling within the policy scope for reducing vulnerability under these circumstances. This points towards the desire for a transition towards a transformational approach to adaptation. There is as yet very little analysis on the size of the present adaptation gap, nor of the range of policy responses that might be possible. 
More purposeful movements in adaptation to extremes can be identified from the recent past. In particular, the Pitt Review (2007) on national flood risk management and the NHP have stimulated local authorities and GLA agencies to review provision and undertake local adaptations (GLA 2011). Both have served to improve outcomes and procedures to deliver resilience, but have been less successful in fostering local actors to consider transition to transformational policy spaces for adaptation. In contrast, the emergent self-reliance orientation of the dominant resilience agenda indicates the significance of autonomous incremental transition for constraining transitions towards more transformative adaptation.

\section{Acknowledgments}

Research reported in this paper was undertaken as part of the Belmont Forum funded Transformation and Resilience on Urban Coasts (TRUC) project. This project was supported by Japan Society for the Promotion of Science, the UK Natural Environment Research Council and Economic and Social Research Council (NE/L008971/1), the German Research Foundation (GZ: BI 1655/1-1), The Ministry of Earth Sciences, Government of India (MoES/01-CZM/Truc/2013), and US National Science Foundation (1342966).

\section{References}

Ajibade, A, Agboola J and Pelling, M (2016). Adaptation transitions in Lagos. Journal of Extreme Events, in press.

Béné, C, Godfrey Wood R, Newsham A and Davies, M (2012). Resilience: New Utopia or New Tyranny? Reflection about the potentials and limits of the concept of resilience in relation to vulnerability-reduction programmes. IDS Working Paper 405, Institute of Development Studies, UK.

GLA (2006). London's Urban Heat Island: A Summary for Decision Makers. London: Greater London Authority.

GLA (2009). Regional Flood Risk Appraisal. www.london.gov.uk/mayor/strategies/sds/ docs/regional-flood-risk09.pdf.

GLA (2011). The London Climate Change Adaptation Strategy. London: GLA. www. london.gov.uk.

Harvey, D (2010). The Enigma of Capital: And the Crisis of Capitalism. Profile Books: London.

Howlett, M and Ramesh, M (2003). Studying Public Policy: Policy Cycles and Policy Subsys tems. Toronto: Oxford University Press.

Inderberg, $\mathrm{H}$ and Eikeland, PO (2009). Limits to adaptation: Analysing institutional constraints. In: Adger N, Lorenzoni I and O’Brien K (eds.) Adapting to Climate Change: Thresholds, Values, Governance. Cambridge: Cambridge University Press. 
Kates, RW, Travis WR and Wilbanks, TJ (2012). Transformational Adaptation When Incremental Adaptations to Climate Change are Insufficient. Proceedings of the National Academy of Sciences of the United States of America, 109(19): 7156-7161.

Link, H and Solecki, W (2017). Adaptation transitions in New York. Journal of Extreme Events, in Press.

Local Government Association (2014). Future Funding Outlook 2014: Funding Outlook for Councils to 2019/20. London: LGA. http://www.local.gov.uk.

Measham, TG, Preston BL, Smith TF, Brooke C, Gorddard R, Withycombe G and Morrisoon, C (2011). Adapting to climate change through local municipal planning: Barriers and challenges. Mitigation and Adaptation Strategies for Global Change, 16(8): 889-909.

Nathan, M and Carmon, N (2015). Affordable housing plans in London and New York: Between Marketplace and Social Mix. Housing Studies, 30(7): 993-1015.

Rajeev, P, Narayanan P, Ramachandran P and Ramachandran, R (2016). Adaptation transitions in Kolkata. Journal of Extreme Events, in press.

Nishi, M, Pelling M, Solecki B, Yamamuro M and Krain, S (2016). Adaptation transitions in Tokyo. Journal of Extreme Events, in press.

Parker, DJ (1999). Disaster response in London: A case of learning constrained by history and experience. In: J. K. Mitchell (ed.) Crucibles of Hazard: Mega-Cities and Dsasters in Transition. Tokyo: United Nations University Press.

Pitt Review (2007). Learning Lessons from the 2007 Floods. nationalarchives.gov.uk.

Pelling, M (2011). Adaptation to Climate Change: From Resilience to Transformation. London: Routledge.

Pelling, M, High C, Dearing J and Smith, D (2007). Shadow spaces for social learning: A relational understanding of adaptive capacity to climate change within organisations. Environment and Planning A, 40(4): 867-884.

Pelling, M, O’Brien K and Matyas, D (2015). Adaptation and transformation. Climatic Change, 33(1): 113-127.

Public Health England (PHE) (2014). Heatwave Plan for England. Protecting Health and Reducing Harm from Severe Heat and Heatwaves. London: Public Health England.

Rotmans, J, Kemp R and van Asselt, M (2001). More evolution than revolution: Transition management in public policy. Foresight, 3(1): 15-31.

Revi, A, Satterthwaite DE, Aragón-Durand F, Corfee-Morlot J, Kiunsi RBR, Pelling M, Roberts DC and Solecki, W (2014). Urban areas. In: CB Field, VR Barros, DJ Dokken, KJ Mach, MD Mastrandrea, TE Bilir, M Chatterjee, KL Ebi, YO Estrada, RC Genova, B Girma, ES Kissel, AN Levy, S MacCracken, PR Mastrandrea and LL White (eds.) Climate Change 2014: Impacts, Adaptation, and Vulnerability, Part A: Global and Sectoral Aspects. Contribution of Working Group II to the Fifth Assessment Report of the Intergovernmental Panel on Climate Change, Cambridge: Cambridge University Press, pp. 535-612.

Royse, KR, Horn D, Eldridge J and Barker, K (2010). Flooding and subsidence in the Thames Gateway: Impact on insurance loss potential. Geophysical Research Abstracts, 12.

Schipper, L and Pelling, M (2006). Disaster risk, climate change and international development: Scope and challenges for integration. Disasters, 30(1): 19-38. 
Solecki, W, Pelling M and Garschagen, M (2017). Transitions between risk management regimes in megacities, Ecology and Society, in review.

Stone, DA (2002). Policy Paradox: The Art of Political Decision Making. New York: WW Norton.

Travers, T, Sims S and Bosetti, N (2016). Housing and Inequality in London. Centre for London. www.creativecommons.org.

Tremeer, CJAM, Dewulf A and Biesbroek, GR (2016). Transformational change: Governance interventions for climate change adaptation from a continuous change perspective. Journal of Environmental Planning and Management.

UK Government (2007). Learning Lessons from the 2007 Floods: The Pittt Review. http:// webarchive.nationalarchives.gov.uk/20100807034701/http:/archive.cabinetoffice. gov.uk/pittreview/thepittreview/final_report.html.

Zaidi, Z and Pelling, M (2015). Institutionally configured risk: Assessing urban resilience and disaster risk reduction to heatwave risk in London. Urban Studies, 52(7): 1218-1233. 